\title{
Liga de Prevenção à Cegueira - 29 anos de ensino, pesquisa e assistência em oftalmologia
}

\author{
Juliana Mika Kato ${ }^{1}$, Luis Felipe Yassuki Ohnishi', Alex Haruo Higashi', \\ Ahlys Ayumi Nagai ${ }^{1}$, Pedro Carlos Carricondo ${ }^{2}$
}

Kato JM, Ohnishi LF, Higashi AH, Nagai AA, Carricondo PC. Liga de prevenção à cegueira - 29 anos de ensino, pesquisa e assitência em oftalmologia. Rev Med (São Paulo). 2015 jan.-mar.;94(1):64-5.

\section{INTRODUÇÃO}

Uma parcela significante das doenças sistêmicas mais prevalentes em nosso meio vem acompanhada de acometimento ocular e muitas doenças oftalmológicas exigem atendimento imediato e cuidados específicos para evitar-se a cegueira. O curso de Oftalmologia da graduação abrange os temas essenciais à adequada formação do médico generalista, porém carece de treinamento prático e cirúrgico. A fim de suprir tal deficiência, a Liga de Prevenção à Cegueira foi fundada em 1985 como alternativa para aprofundar os conhecimentos na área, aproximar-se da prática oftalmológica e atender indagações profissionais futuras.

\section{OBJETIVO}

O intuito desse estudo é divulgar as atividades da Liga e analisar a avaliação dos membros. Estrutura. A estrutura administrativa é formada por três acadêmicos (um Presidente e dois Diretores-Gerais), um professor supervisor e quatro residentes em seu último ano de formação. Os integrantes são treze alunos do segundo ao quinto ano de Medicina, selecionados a partir de uma prova baseada no Curso Introdutório.

\section{ATIVIDADES}

São ministradas aulas teóricas semanais, aulas práticas no ambulatório para manejo dos aparelhos, treinamento microcirúrgico em olhos de porco, acompanhamentos no Pronto-Socorro e no Centro Cirúrgico.

A Liga também convida os alunos a participarem da Campanha Visão do Futuro aos sábados, onde realizam exames de acuidade visual, mobilidade ocular, dilatação, fundoscopia e refração em alunos do ensino fundamental da rede pública do Estado de São Paulo.

Trata-se de uma campanha de prevenção em parceria com o Fundo Social de Solidariedade e secretarias de Estado de Saúde e Educação. Caso haja interesse do aluno, são indicados professores que ofereçam projetos de iniciação científica. Nos últimos três anos, a Liga teve oito trabalhos aprovados, sendo cinco pôsteres, duas apresentações orais e uma publicação na Revista Brasileira de Oftalmologia.

\section{ATIVIDADES COMPLEMENTARES}

Além de promover o Curso Introdutório e o calendário de eventos, a Diretoria Acadêmica conduz

$1^{\circ}$ lugar Prêmio Painéis - Liga Acadêmica no 33 COMU - Congresso Médico Universitário da FMUSP, SP, 31 de out. a 02 de nov. de 2014.

1. Acadêmicos de Medicina da Faculdade de Medicina da Universidade de São Paulo.

2. Orientador, Faculdade de Medicina da Universidade de São Paulo. 
atividades de perspectivas nacionais. Participa ativamente da Comissão Organizadora do Interligas de Oftalmologia, maior evento acadêmico da especialidade no país, e auxilia a organização do Encontro Nacional das Ligas Acadêmicas de Oftalmologia.

\section{AVALIAÇÃo}

Foi aplicado um questionário de avaliação aos membros dos últimos cinco anos. Verificou-se que os principais motivos de procura pela liga são o interesse em seguir a especialidade na residência médica e aprimorar os estudos na área.

O aprendizado teórico, o wet-lab e a utilização dos equipamentos compõem os principais pontos positivos; já a quantidade de pacientes vistos destaca-se como ponto negativo.

\section{DISCUSSÃO E PERSPECTIVAS FUTURAS}

As aulas práticas de fato são dedicadas ao manuseio dos aparelhos em detrimento da consulta oftalmológica, pois tal competência básica é pré-requisito para uma assistência adequada. Pretende-se, então, incentivar a presença facultativa no PS e fundar uma Disciplina Optativa em Oftalmologia para complementar as atividades da Liga sem sobrecarregar o horário usual.

Além disso, criou-se um workshop de Oftalmoscopia em parceria com a Extensão Médica Acadêmica, extensão ligada à atenção primária, e há uma prevista associação com a Liga de Diabetes no setor ambulatorial para atender as dificuldades referidas. 